\title{
Quanto de memória há no saber-fazer do palhaço? As questões contemporâneas sobre o patrimônio cultural a partir do trabalho de um grupo familiar de circo-teatro
}

How much memory is in the know-how of clown? Contemporary issues about cultural heritage from the work of a circus-theater family group

Darlan De Mamann Marchi ${ }^{1}$ 


\section{Resumo}

O Circo-teatro ou Teatro de Lona do Bebé, atuante na região sul do estado do Rio Grande do Sul, dá continuidade a uma antiga prática teatral itinerante. Os vários espetáculos do repertório do grupo são releituras que mesclam elementos do passado a situações e temas contemporâneos e que possuem como protagonista o palhaço Bebé, o pai da família e proprietário do circo. Através da pesquisa foi possível verificar que o fazer teatral do grupo vincula-se estreitamente a uma memória familiar, sob a qual estão os fatores organizadores do trabalho. Pensar sobre a patrimonialização da prática teatral popular da qual o grupo/ família é detentora traz consigo os desafios contemporâneos do debate sobre o patrimônio cultural.

Palavras-chave: Cultura popular; circo-teatro; memória; patrimônio cultural

\section{Abstract}

The circus-theater or Lona'sBebé Theatre, active in southern state region of Rio Grande do Sul, continues its itinerat theater practice. The several shows of group are readings that mix elements of the past whit contemporary situations and issues which have as protagonist the Clown called Bebé, the father of the family and circus owner. Through of research we found that the work of theater group is closely linked to a family memory, under which they are organizers factors at work. Think about the recognition process as cultural heritage of theater practice popular of which group/ family has of them contemporary challenges about the debate on cultural heritage.

Keywords: Popular culture; circustheater; memory; cultural heritage

ISSN: 1414.5731

E-ISSN: 2358.6958

${ }^{1}$ Doutorando do Programa de Pós Graduação em Memória Social e Patrimônio Cultural; Universidade Federal de Pelotas. Bolsista Capes. darlanmarchi@gmail.com 


\section{Cultura Popular e o circo-teatro}

A classificação de uma manifestação como parte da "cultura popular" necessita ser problematizada, voltando-se às questões conceituais que marcaram a historiografia mais recente, como no caso das três noções definidas por Chartier (1990, p.27): representação, práticas e apropriação. Ou seja, as semelhanças e idiossincrasias entre as formas como essa manifestação é vislumbrada no campo das ideias, a forma como ela é vivida e praticada no cotidiano e a maneira como ela é absorvida pelas comunidades, sendo formadora de memórias compartilhadas, delineiam um discurso coeso e que permite a sua propagação ao longo do tempo.

Apoiando-se nesse entendimento, deve-se levar em consideração a dinamicidade das manifestações que são classificadas como populares e os entrecruzamentos do popular e do erudito. Pode-se observar um olhar das ciências para o estudo da cultura popular a partir do que Burke (1989, p.31) chamou de "a descoberta do povo", ou seja, do movimento do final do século XVIII e do início do século XIX, no qual a cultura tradicional dos setores subalternos passa a ser vislumbrada pela intelectualidade do período. Por conseguinte, Hobsbawn (2006, p. 11) expressa que "as sociedades que se desenvolveram a partir da Revolução Industrial foram naturalmente obrigadas a inventar, instituir ou desenvolver novas redes de convenções e rotinas com uma frequência maior do que antes", o que ocasionou o diálogo entre aspectos culturais múltiplos, desde os mais rígidos e esteticamente elaborados pela cultura burguesa até os da linguagem popular.

As manifestações ditas populares, estudadas na atualidade, representam, de alguma forma, expressões e modos de vida que resistem temporalmente à imposição cultural hegemônica. No entanto, a complexidade dessa relação é tamanha que, muitas vezes, o grupo menosprezado pela ordem vigente acaba por reelaborar aspectos de sua cultura englobando diferentes aspectos da cultura dominante. Nesse meandro, características do popular e do erudito, mesmo abordadas de forma antagônica, acabam por dialogar, influenciando-se mutuamente em diferentes momentos. Com base nisso, para Chartier (1995, p. 181), "o destino historiográfico da cultura popular é, portanto, ser sempre abafada, recalcada, arrasada, e, ao mesmo tempo, sempre renascer das cinzas". Ou seja, é neste processo de arraso e ressurgimento, manutenção e transformação que o popular deve ser problematizado, a fim de se compreender as imposições de algumas forças e teias de poder.

Partindo dessa perspectiva, é que se analisa o caso do circo-teatro, compreendendo essa expressão da cultura cênica como um lugar de intercâmbio do popular e do erudito. Uma manifestação que agrega características de uma sociedade moderna, capitalista e industrializada, mas gestada em tempos da teatralidade da rua, do grotesco, do escárnio e do riso. Henri Bergson fala do riso como um agente que cumpre uma função social, o riso seria o "mecânico aplicado sobre o vivo", ou seja, quando se ri de alguma situação, que se coloca como ridícula frente ao oficialmente instituído, a ordem é reconstituída na sociedade (Alberti, 2011, p. 185).

O palhaço, figura central na tradição do circo-teatro, é o que dá sentido à manifestação. Herdeiro de um saber-fazer rir, como é o caso do Teatro do Bebé aqui ana- 
lisado, terceira geração de cômicos na mesma família, esses personagens há muitos séculos estão inseridos nas sociedades. Presentes em diferentes festas populares e encenações ao longo do tempo, personagens grotescos, como miseráveis espertalhões, velhos com enorme apetite sexual, gigantes glutões, humanos com deformidades físicas, firmaram-se como figuras recorrentes no campo do humor.

Nesse território, os apetites humanos e todas as formas de expressão que remetem ao baixo ventre estão presentes naquilo que Bakhtin chama de realismo grotesco, em que "o elemento material e corporal é profundamente positivo" e vai se colocar na oposição de uma "separação das raízes materiais e corporais do mundo". O autor completa esse pensamento afirmando que "o traço marcante do realismo grotesco é o rebaixamento, isto é, a transferência ao plano material e corporal, o da terra e do corpo na sua indissolúvel unidade, de tudo que é elevado, espiritual, ideal e abstrato" (Bakhtin, 2010, p.17).

Assim, o circo-teatro se constitui como uma expressão que mescla o teatro popular das ruas, com a modernidade do circo de picadeiro e as formas teatrais como o teatro de revista e de costumes. Ainda no princípio do século XX, o palhaço Benjamin de Oliveira ${ }^{2}$ despontou como o artista que levou o teatro cômico como atração principal no espaço da lona. Na década de 20 do século passado é que o circo-teatro tem seu apogeu, espalhando-se pelo interior do país, com destaque nas regiões sul, sudeste e nordeste nas décadas de 1930 e 1940 (Andrade Jr., 2000, p.8). Nesse segundo período, desenvolveram-se os melodramas circenses, que foram definindo uma dramaturgia própria dessa modalidade teatral. A terceira geração do circo-teatro desponta na década de 50, sofrendo um grande declínio nos anos 60 e 70, quando várias empresas de circo-teatro encerraram suas atividades, pela disseminação da televisão ou pela mudança do gosto do público (Pimenta, 2005, p.24).

O Teatro do Bebé, desafiando essa lógica, se destaca justamente nesse período de "decadência". Mesmo tendo a família Almeida ${ }^{3}$, passado pelos anos de destaque do circo-teatro no século passado, o formato teatral que a companhia desempenha hoje é resultado dessa adaptação e reelaboração da crise. Assim, como outros circosteatro contemporâneos, provenientes do diálogo do circo com o teatro, do picadeiro com o palco, do show de variedades com o espetáculo cênico melodramático, na atualidade, é o espetáculo cômico que dá sentido à atividade, com o palhaço como a figura principal da atividade.

Disseminados entre a população, os circos-teatro levavam ao público diferentes gêneros teatrais, como o melodrama ${ }^{4}$. Entretanto, se sobressaihoje, nos teatros familiares que ainda perduram, quase que exclusivamente o gênero da comédia. $O$ riso e sua soberania idílica que, mesmo com a modernidade e a instabilidade do século XX, permitiu o prosseguimento dessa tradição teatral e que, como foi discutido anteriormente, conecta o homem à sua condição mundana.

\footnotetext{
${ }^{2}$ Ver a obra de Ermínia Silva: "Circo-teatro: Benjamin de Oliveira e a teatralidade circense no Brasil” de 2007.

${ }^{3}$ Família de circo-teatro da qual pertence José Ricardo de Almeida, o palhaço Bebé.

${ }^{4}$ Sobre os melodramas no circo-teatro, consultar Daniele Pimenta (2005) e Elaine Santos (2013).
} 


\section{O Circo-teatro Bebé, a vida itinerante e as memórias familiares}

O trabalho com teatro itinerante na família Almeida iniciou em 1929, no interior de São Paulo, onde nasceu o patriarca José Epaminondas de Almeida, que se tornaria o cômico de nome artístico Nhô Bastião, trabalhando em dupla com a sua irmã Isolina de Almeida, a Nh'Ana no Circo Politeama, ou Circo-teatro Politeama Oriente, criado pela dupla ${ }^{5}$. No pavilhão os artistas apresentavam um show de variedades, mas com foco específico no teatro, principalmente no melodrama e em esquetes cômicos. Com uma estrutura desmontável em madeira e zinco, era transportado para diferentes cidades, onde os artistas permaneciam apresentando diferentes peças do repertório durante uma temporada específica.

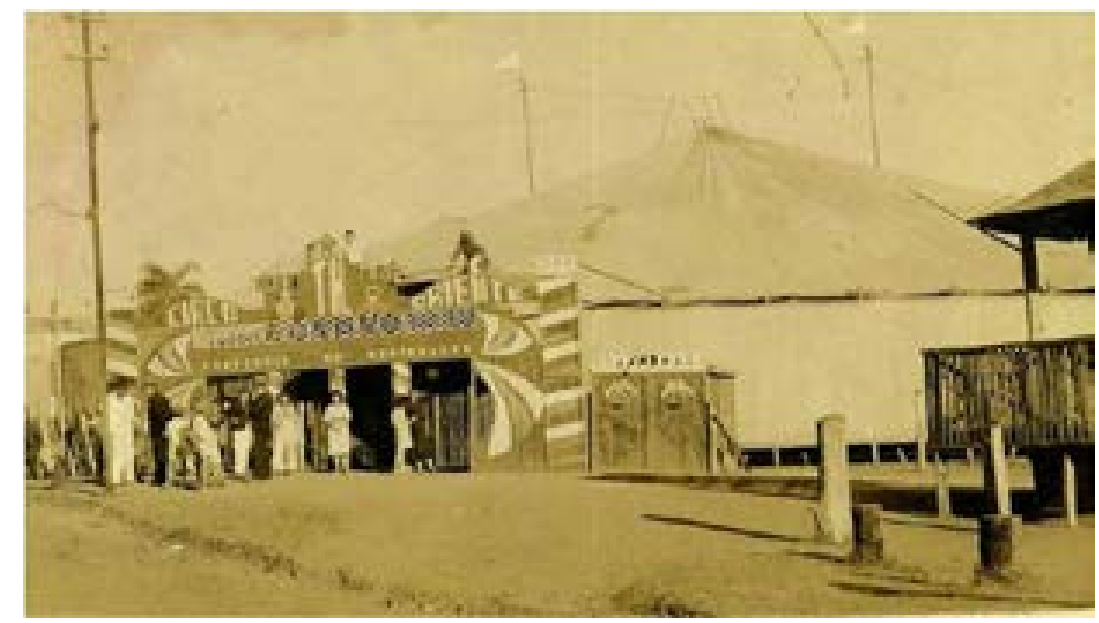

Figura 1 - Circo-teatro Politeama Oriente. Interior de São Paulo no ano de 1935. Fonte: Blog Teatro Nh'Ana. Disponível em: < teatronhana. blogspot.com.br201102teatro-nhana-historia-e-sucesso.html> Acesso em 25 ago. 2013

O Politeama passou a viajar por algumas cidades de Minas Gerais, São Paulo, Santa Catarina, Paraná e Rio Grande do Sul. No final da década de 1940 e início de 1950, encontram-se registros da passagem do grupo pelo Rio Grande do Sul, como o que ocorre em São Leopoldo, onde há promulgação de uma lei de nำ 178/50 de 10 de abril de 1950, que "concede Isenção de taxa de caridade a Empresa Teatral Politeama Oriente, sobre um espetáculo beneficente". Referindo-se a essa mesma tournée da década de 50, José Ricardo de Almeida, o palhaço Bebé, lembra que o pai Nhô Bastião não era ainda tão conhecido, e, por trabalhar como cômico caipira, tinha certa dificuldade de conquistar a plateia, algo que foi sendo superado aos poucos. Segundo ele,

[...]o gaúcho aqui não é muito chegado no caipira, ele é chegado no palhaço [...] e meu pai era caipira. [...] tinha um aqui que era um excelente cômico, mas não tinha tantos recursos de improviso, que era o Biduca. Mas era o Biduca porque era palhaço então era o bam-bam-bam do Rio Grande do Sul (informação verbal)7.

\footnotetext{
5 Nh'Ana casa com um funcionário do Politeama e compra a parte do irmão no teatro, criando em Santa Catarina "Teatro Nh'Ana" na segunda metade da década de 1930 (Andrade Júnior, 2000). Nhô Bastião, por sua vez, adquire outro pavilhão e segue trabalhando com a família. A mesma separação ocorre com Bebé e o irmão Serelepe, mais recentemente, cada um cria o seu teatro juntamente com sua esposa e filhos. 6 Disponível em: http://www.jusbrasil.com.br/legislacao/663579/lei-178-50-sao-leopoldo-0. Acesso em 13 nov. 2012.

7 José Ricardo de Almeida (Bebé). Entrevista concedida ao autor em 19 ago. 2012. Pelotas-RS.
} 


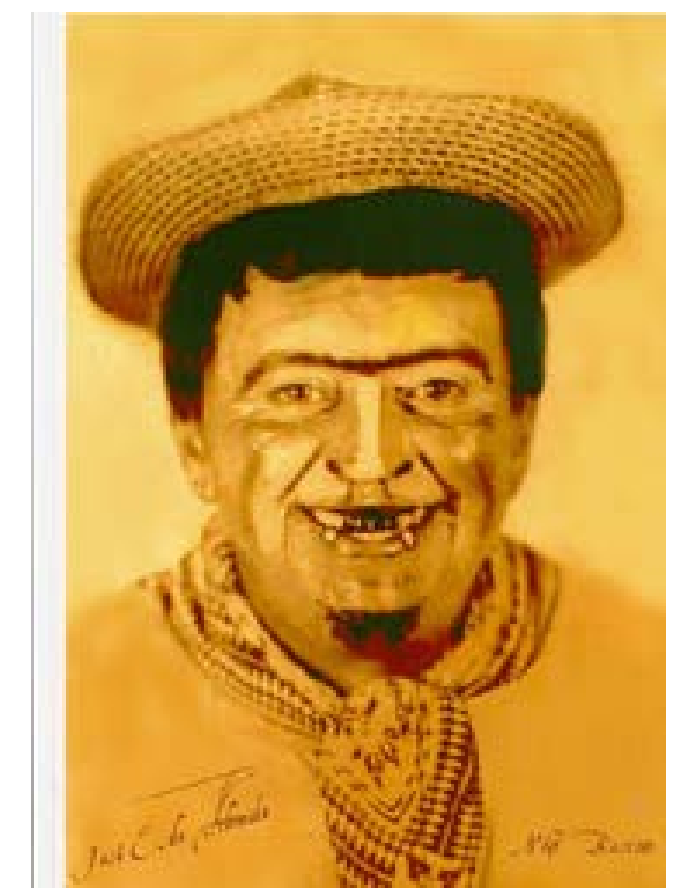

Figura 2 - José Epaminondas de Almeida - Cômico caipira Nhô Bastião. Fonte: Arquivo da família Almeida.

Desse período, Bebé guarda uma cópia do jornal Gazeta de Santa Cruz do Sul, do dia 14 de julho de 1950, que fala da temporada da companhia naquela cidade:

Vem sendo $[\ldots] 8$ sucedido em sua temporada nesta cidade o admirável conjunto teatral conduzido pelo consagrado artista nacional Nhô Bastião (José Almeida), ora nessa cidade com seus pavilhões próprios instalados na Praça da Matriz. Lutando de início contra fatores de ordem adversa, o famoso teatro de emergência conseguiu realizar o verdadeiro milagre de apresentar casa superlotada durante dias consecutivos da semana.

Como se pode perceber, os teatros de emergência, como a imprensa registrou os circos-teatro em inúmeros anúncios e reportagens, através de sua estrutura provisória e de temporadas específicas, representavam nos pequenos núcleos urbanos (a grande maioria sem espaços cênicos fixos, ou sem periodicidade de espetáculos em cartaz) uma forma de lazer e de acesso ao teatro, mesmo que temporariamente.

Após o falecimento de Nhô Bastião, o filho mais velho José Maria, irmão de Bebé por parte de pai, daria seguimento ao circo-teatro da família, agora com o nome de

8 Sentença rasurada no documento. 
Teatro Serelepe ${ }^{9}$, que estreou com esse nome no ano de 1962 na cidade de Cruz Alta. De lá até a atualidade, a família permaneceria então ligada ao estado do Rio Grande do Sul, viajando no interior do estado primeiramente com o pavilhão de zinco e mais tarde com a estrutura da lona circense. Nesse período, José Maria já havia se casado com a atriz Lea Benvenuto, filha de uma família circense que trabalhava com Nhô Bastião, José Ricardo, e se casaria mais tarde com a irmã de Lea, Ana Maria Benvenuto com quem teve nove filhos, muitos dos quais ainda hoje trabalham no Teatro do Bebé. Conforme Andrade Júnior (2000), mediados pelo trabalho, os artistas que adentravam o espaço da lona acabavam fazendo parte da "família circense", o que também levava aos casamentos entre as famílias que ali atuavam. Assim, os laços profissionais se reconfiguravam em laços de sangue.

No ano de 1976, José Ricardo passou a se especializar no trabalho cômico, primeiramente como palhaço para crianças, e logo aprimorando a técnica no trabalho diário e ganhando espaço no Teatro Serelepe, onde o irmão José Maria era o cômico principal. Conforme José Ricardo, era o ano de 1979 quando seu irmão resolveu parar com o teatro por um tempo e ele, já com seu personagem Bebé, precisou continuar com o trabalho no Teatro Serelepe. Anos mais tarde, o irmão voltaria e os dois prosseguiriam como sócios no Teatro Serelepe. Essas idas e vindas passaram a ser características dentro do grupo até a formação do circo-teatro de cada família em separado. Segundo afirma Bebé: "família grande sempre tem as suas rusgas, nossa família era enorme, trabalhava todo mundo junto aqui [...] eram 40 pessoas na companhia, aí não tinha como sobreviver, hoje em dia não sobrevive com 40 pessoas" (informação verbal) ${ }^{10}$.

O circo-teatro definia-se assim como um espaço onde estavam inseridas relações de trabalho, familiares e artísticas, todas interligadas entre si. Conforme salienta Silva (2009, p. 30), "[...] a vida dos que vivem 'debaixo da lona' possui uma característica singular, pois é sempre um viver comunitário. Sua estrutura básica é de agrupamento de famílias, que vivem e trabalham no mesmo local". Sendo assim, como em qualquer outro espaço de relações, se convivia com questões de ordem de conflitos e de disputas de poder, em que está colocada a procura por um espaço de destaque no meio profissional. Essas relações podem ser exemplificadas no caso de Bebé, quando esse afirma: “[...] claro que eu não podia ficar seguindo com o Serelepe eternamente. Eu ia só enaltecer o Serelepe, né. O palhaço era o Bebé e estando no Serelepe eles não iam falar no Bebé [...]" (informação verbal) ${ }^{11}$.

Desde 2006, a família fixou residência na cidade de Pelotas/RS, cidade onde Bebé já possuía reconhecimento, pela adesão do público ao trabalho e também pelas relações de amizades conquistadas nas primeiras temporadas na década de 1990. A família adquiriu um imóvel e, desde então, o grupo tem partido de Pelotas para temporadas de espetáculos em diferentes cidades do Rio Grande do Sul. A

90 Teatro de Lona Serelepe segue em atividade na região norte e noroeste do Rio Grande do Sul até os dias atuais. O palhaço Serelepe é interpretado hoje por Marcelo Benvenuto de Almeida, filho de José Maria de Almeida. A trajetória do núcleo familiar Serelepe foi abordada em: SANTOS, Elaine. Entre lágrimas e risos: os serelepes e a memória do teatro itinerante. Tese (doutorado). Programa de Pós-graduação em Letras. Centro de Artes. Universidade Federal de Santa Maria, 2013.

10 José Ricardo de Almeida (Bebé). Entrevista concedida ao autor em 19 ago. 2012. Pelotas-RS

11 José Ricardo de Almeida (Bebé). Op. Cit. 
praça dura ${ }^{12}$ cerca de 30 a 45 dias, em que são apresentados espetáculos diários de um repertório de mais ou menos 30 peças, com ingressos a valores populares que variam de preço dependendo da maior proximidade da cadeira com o palco. Os espetáculos são apresentados sob a lona, que possuía inicialmente lugares para 500 pessoas $^{13}$, sendo armada em terrenos nos bairros de Pelotas ou em outras cidades do Rio Grande do Sul, por onde o grupo viaja com os ônibus e trailers.

Uma das características marcantes da fase contemporânea do grupo foi a gradual extinção dos melodramas do repertório das temporadas. Os espetáculos melodramáticos eram parte importante dos espetáculos até os anos 1970-1980. Na década de 1990, quando criou seu próprio teatro, Bebé permaneceu com os melodramas por algum tempo, mas logo foram cedendo lugar à comédia. Mario Bolognesi, em 1999, acompanhando o Teatro do Bebé, na cidade de Restinga Seca, relata ter assistido a uma noite de espetáculos nos moldes tradicionais como se estruturava o circo-teatro: primeiramente um melodrama e posteriormente uma comédia com o palhaço. Segundo o pesquisador, o melodrama, marcado pela interpretação forçada e por mensagens moralizantes, mostrou-se enfadonho para o público (Bolognesi, 2003, p.169). Todavia, o drama ainda hoje é lembrado pelos artistas com grande saudosismo:

Eu gosto do drama, porque no drama tu pode mostrar mais assim o teu trabalho. E uma comédia não, é mais livre, tu pode improvisar, tu pode sair um pouco do texto, [...] e o drama não, no drama tu tem que acompanhar aquele texto, mas só que tu acompanha o texto ao mesmo tempo tu pode atuar [...] eu não sei, acho que é do gosto de cada um, mas eu prefiro o drama (informação verbal) 14.

As regiões com maior abrangência do Teatro do Bebé são o litoral sul, a campanha e o centro-sul do Rio Grande do Sul, com algumas incursões para a fronteiraoeste e o litoral norte. O espaço de tempo entre uma temporada e outra em cada cidade acontece segundo a estratégia do grupo que é a de "deixar saudade", conforme denomina Bebé. Como trabalham com um repertório fechado e não há renovação dos espetáculos, costumam demorar em voltar e realizar os mesmos espetáculos numa localidade.

Uma vez que o palhaço é a figura forte do circo-teatro e que marca a memória do público, algum tempo sem ir a uma determinada cidade permite, quando do retorno, a garantia da casa cheia, independente das peças serem as mesmas, pois são o palhaço e as situações risíveis que este cria que atraem o público. Não há uma organização de um roteiro pré-estabelecido de temporadas por ano, elas ocorrem conforme as questões de infraestrutura que o grupo necessita para se instalar, assim como as autorizações e as burocracias necessárias. Bebé afirma sobre "a importância

\footnotetext{
12 Termo pelo qual os artistas do circo-teatro do Bebé se referem a temporada de espetáculos.

13 Em 20120 Teatro do Bebé funcionou momentaneamente em uma estrutura improvisada, destas alugadas por empresas especializadas para feiras e eventos. No ano de 2013, na cidade de Rio Grande, o grupo passou a atuar com seu espaço próprio remodelado (Figura 4), porém mais reduzido, de maneira a adaptar-se ao tamanho dos escassos terrenos disponíveis nos bairros das cidades e também à demanda de público. 0 número de lugares foi diminuído para 400 espectadores.

14 Silvério de Almeida. Sobrinho do palhaço Bebé e que desempenha o papel de partner ou escada para o cômico. Entrevista concedida ao autor em 28 jun. 2012. Pelotas-RS.
} 
de ir [para as cidades] pra você poder estar sempre vivo na lembrança" (informação verbal) ${ }^{15}$, o que demonstra a estratégia de retorno às mesmas praças depois de um período de tempo.

Diversos aspectos estéticos do trabalho teatral do século passado perduram no Teatro do Bebé, mesmo com as adaptações sofridas nos últimos tempos. O cenário, com mobiliário e objetos de cena realista, divide espaço com um telão pictórico com uma paisagem que localiza o lugar onde a história se passa. Estilo marcante do período naturalista do final do século XIX, a caracterização do espaço cênico é mantida com cuidado pelo grupo.

Diferentemente dos espetáculos montados por grupos profissionais, com atores provindos de diferentes lugares e experiências, no Teatro do Bebé não há ensaio dos espetáculos. Assim como outros grupos de circo-teatro, forjados no trabalho contínuo e nas relações pessoais e familiares de um repertório que se repete e é compartilhado por todos, na família Almeida, quando indagados sobre os ensaios, afirmam não serem necessários, pois basta ler o texto, passá-lo com alguém, e ser orientado do que fazer em cena apenas quando há um ator ou atriz novos que não assistiram ao espetáculo.

Com títulos como Bebé e a maldição do lobisomem, Bebé e sua família na capital, Bebé, o soldado recruta, Bebé, o pai de Santo entre outros, os espetáculos são parte de um repertório compartilhado com outros grupos/famílias de circo-teatro, alguns sem uma autoria precisa, onde ocorre a troca do cômico principal na atuação e também no título, o que demonstra a circularidade desses espetáculos e uma rede existente entre essas companhias familiares. Entretanto, esses textos passaram do escrito ao vivido, sendo ressignificados através da atuação do cômico e de seus elencos familiares, reinventados através da prática diária e repassados pela oralidade.

Andrade Jr. (2000, p. 45) afirma que os artistas de circo-teatro costumavam manter aquilo que já tinha dado certo em outras montagens, não alterando o que já estava pronto. A permanência de alguns textos, cenas e ações entre uma peça e outra são perceptíveis no caso do Teatro do Bebé, porém, o que se sobrepõe é a inventividade do artista e o domínio ágil da técnica do improviso, além da inserção de questões contemporâneas e de piadas atuais que fazem sucesso junto ao público e marcam a sua performatividade.

Diversos espetáculos do Teatro do Bebé trazem questões de conflitos familiares para a cena, permeados pela comicidade, atravessada muitas vezes pelo erotismo e pela picardiado palhaço, personagem que destoa de um ambiente realista em que a cena está colocada. Nesse ambiente, cenas do cotidiano familiar também passam para o palco ${ }^{16}$. São atores de um grupo familiar que se inspiram em questões internas e as levam a cena, exacerbando-as comicamente. Os papéis de cena teatral e da vida real se misturam no espaço cênico e constituem a linguagem do circo-teatro. Tornar o cotidiano familiar em um espetáculo risível faz com que as pessoas da plateia se

15 José Ricardo de Almeida (Bebé). Entrevista concedida ao autor em 19 ago. 2012. Pelotas-RS.

16 Na convivência com o grupo, foi possivel observar o entrecruzamento de papéis familiares (em alguns espetáculos Bebé faz o papel de pai, Ana Maria de mãe, os filhos do casal os papéis de filhos), assim como de situações de família, discutidas nos bastidores que são dispositivos momentos de improviso na cena. 
identifiquem com o que assistem e produzam esse ritual cênico. A cena, por sua vez, rompe com a quarta parede e encontra o público, marcando uma performance em que as fronteiras entre a representação cênica e a realidade concreta não possuem marcos bem delimitados.

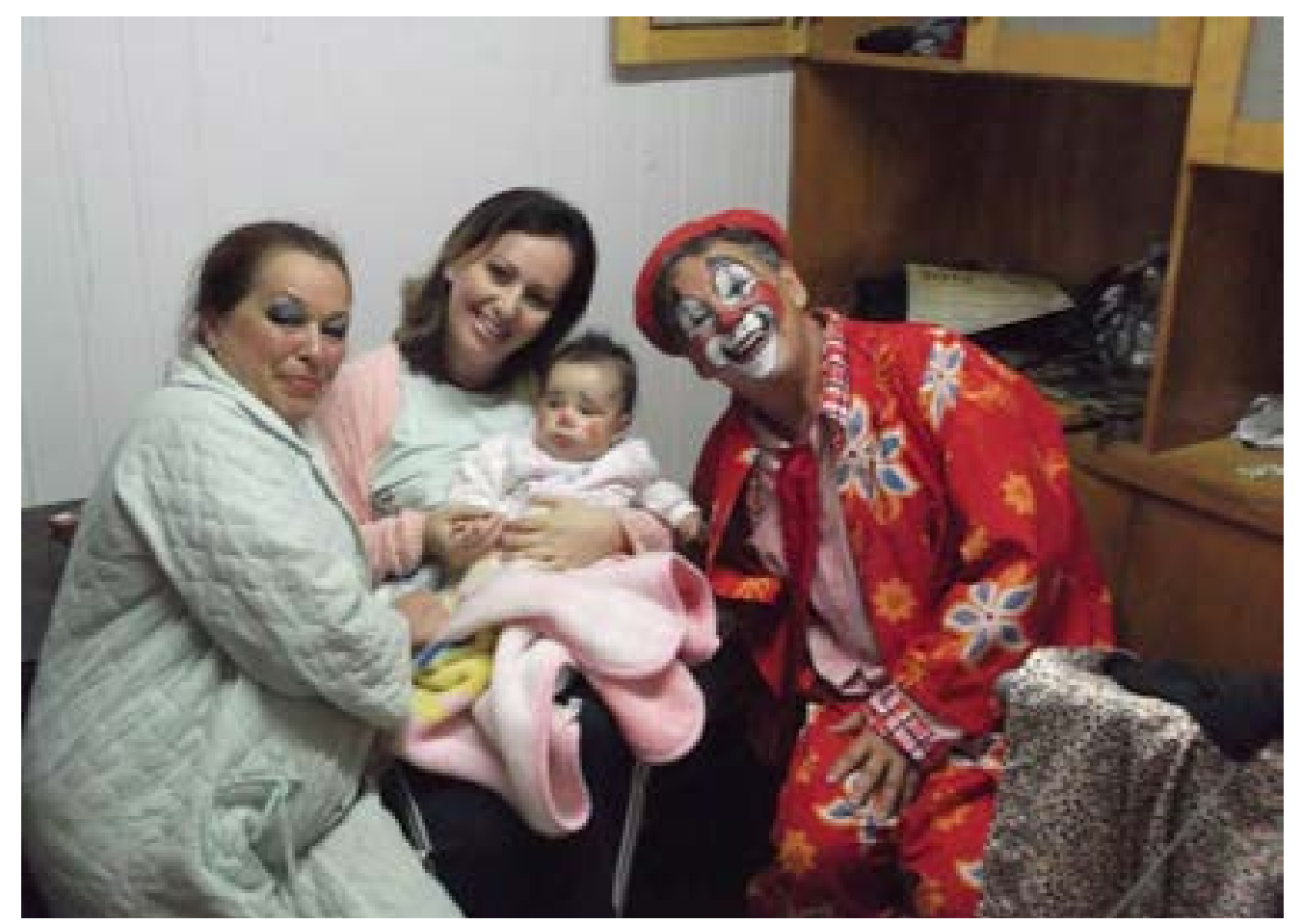

Figura 3 - Bebé após o espetáculo com a esposa Ana Maria a filha e a neta com maquiagem de palhaço, no camarim/ônibus após o espetáculo. Fonte: Foto do autor. 22 abr. 2012. Pelotas-RS.

A centralidade do cômico é algo estabelecido internamente no circo-teatro e significa uma investidura de poder dada a ele por sua eficácia cênica e também pela experiência. Nesse ínterim, Andrade Jr. (2000, p.44) salienta que "a experiência fez com que Nh'Ana se tornasse além de proprietária, dramaturga, atriz, cantora, e também ensaiadora". Bebé, assim como a tia, o pai Nhô Bastião e o irmão Serelepe, assumiu seu posto sucessório e seu espaço de gerência de uma companhia própria, a partir do seu próprio núcleo familiar, passando a ser também o ensaiador dos espetáculos.

O ensaiador, assim denominado pelos integrantes do circo-teatro, ainda hoje é a pessoa responsável pela montagem. Ele “[...] é o gerador da unidade, da coesão interna e da dinâmica da realização cênica" (Roubine, 1998, p. 41). Agente da montagem teatral, o ensaiador figurava numa época em que o texto era a base central do teatro e cabia a ele dar coerência e unidade ao espetáculo, ensaiar os atores, criar o cenário e outras questões técnicas dentro e fora da cena. No caso do Teatro do Bebé, o pai da família é também o personagem central das peças e é aquele que coordena o espetáculo. Sem estruturas dogmáticas exteriores, a não ser aquelas repassadas de pai para filho, são no decorrer da prática cotidiana que os conhecimentos sobre o seu 
fazer no circo-teatro são repassados, aprendidos e modificados.

Essa multiplicidade de funções do artista remete às características do gênero do teatro da Commedia dell'arte, sendo um traço que permanece firmado na figura do artista principal. Essa semelhança está posta nas palavras de Fo, quando discorre sobre os Histriões, os seja, esses sujeitos polivalentes da comédia antiga:

[...] de fato, todo o jogo teatral se apoia em suas costas: o ator histrião é autor, diretor, fabulista. Passa indiferentemente do papel de protagonista para o de "escada", improvisando, esperneando continuamente, surpreendendo não só o público, mas inclusive outros atores participantes do jogo (Fo, 2004, p. 23).

A performatividade cênica do palhaço e o seu resultado positivo enquanto geradora do riso é o que dá a ele reconhecimento, destaque, admiração e respeito. $O$ mesmo trabalho que se alça de estratégias dionisíacas, de uma relevante carga de traços grotescos e que promove o riso no público, é também o que empodera a figura do cômico no espaço do circo-teatro.

A itinerância está sustentada na impermanência dos lugares por onde passa o circo-teatro. Mesmo o palhaço sendo uma figura que traz consigo uma performatividade do modo de fazer, seguindo uma linha pré-estabelecida em relação ao espetáculo, ele está colocado em uma dinâmica da cultura popular, da linguagem das ruas e das particularidades de cada lugar por onde passa.

\section{O saber-fazer do circo-teatro: um olhar patrimonial}

Além da itinerância, a construção coletiva da atividade cênica e o diálogo de diversas manifestações artísticas no espetáculo formam características do trabalho de grupos familiares de circo-teatro. Cabe ainda expressarque no circo-teatro a lona torna-se sala de espetáculo e o picadeiro um palco italiano, promovendo a interação entre o espaço e a prática teatral, linguagens que se mesclam entre a espacialidade/ materialidade e a performance. O termo "teatralidade circense", utilizado por Silva (2007), parte da compreensão do caráter multifacetado do artista popular circense, o que envolve um conjunto de referências adquiridas no decorrer de sua trajetória.

Há entre as heranças culturais dos circenses e as dos lugares para onde migraram cruzamentos ininterruptos, que resultam em continuidades e inovações na construção dos espetáculos. Os circenses ao se apresentarem aqui e ali como acrobatas, ginastas, mágicos, domadores, cantores, músicos, autores e atores, vão realizando trocas de experiências e ressignificações com outros modos de produções artísticas que, por sua vez, também são múltiplas (Silva, 2007, p. 22).

Dessa forma, as memórias do indivíduo, e que são referências definidoras de sua identificação com o mundo que o cerca, e de suas ações no espaço onde está colocado, possuem influência do meio social, com as trocas e relações que estabelece. Para Halbwachs (1990, p. 25-26), uma vez que a pessoa sustenta suas lembranças nas dos outros, ela sente-se mais segura quando as evoca, e, nesse momento, é "como se uma mesma experiência fosse recomeçada, não somente pela mesma pessoa, mas por várias".

Encontra-se assim, nas palavras de Halbwachs, um dos princípios para se com- 
preender a forma como se processa a ligação do sujeito com uma atividade profissional que ocorre em um ambiente familiar. A transmissão do trabalho do cômico popular ao estilo do circo-teatro pode ser observada como uma forma de transmissão de um ofício, já que dela deriva o saber-fazer do ator, o qual se desenvolve dentro das singularidades da vida nômade. Existem, nessa transmissão, alguns pontos comuns dessa singularidade, mas se faz presente também a forma como cada indivíduo adapta isso para sua atividade, no caso, a atividade cênica. Afinal, "[...] é evidente que a cultura adquirida não é uma cópia exata da cultura transmitida. As crianças, em suas interações, modificam a cultura. A sua transmissão não é somente uma repassagem, é uma reinvenção" (Pontes; Magalhães, 2003, p. 122). A dinâmica da permanência e da transformação, própria de uma prática em processo, balizada pela memória e pelas necessidades do presente, se dá no circo-teatro, desde o seu surgimento,nas variações e adaptações dos textos teatrais e dos espaços ocupados nas cidades, e na adaptação da linguagem, tudo conforme as respostas do público.

No Teatro do Bebé, a memória de outros tempos vividos se presentifica nas narrativas familiares, mas é ainda uma memória viva em constante alteração, pois é no trabalho diário, com a consequentetransmissão da prática, que lhe é conferido o caráter tradicional. Uma tradição que é também uma reinvenção cotidiana a qual só se mantém pelo respaldo de um público para quem essa forma de comicidade possui um significado.

A sociedade contemporânea foi moldada dentro de padrões eurocêntricos que reproduziram modelos hegemônicos de compreensão sobre uma ideia de culturaque se pretendeu oficial. Dentro desse paradigma, as expressões da cultura popular, por exemplo, foram tidas como menores frente aos estilos consagrados. 0 circo-teatro, todavia, é uma prática artística que se utiliza domodelo teatral clássico, mas que o ressignifica através da linguagem popular e da inserção de aspectos contemporâneos. A atividade desenvolveu-se em núcleos familiares e tornou-se uma prática hereditária, e, mesmo sendo uma manifestação cultural urbana, não passou ilesaa prejulgamentos no campo das artes. O circo-teatro cumpriu,num primeiro momento, em fins do século XIX e ao longo do século XX, a função de levar as artes cênicas para o interior do Brasil, porém não obteve o mesmo destaque que oteatro clássico na história oficial do teatro brasileiro. A prática do circo-teatro foi afetada quando da profusão dos meios tecnológicos como a televisão (Sousa Júnior, 2008), fator que, no caso do Teatro do Bebé, passou a fazer parte da dinâmica do trabalho. 


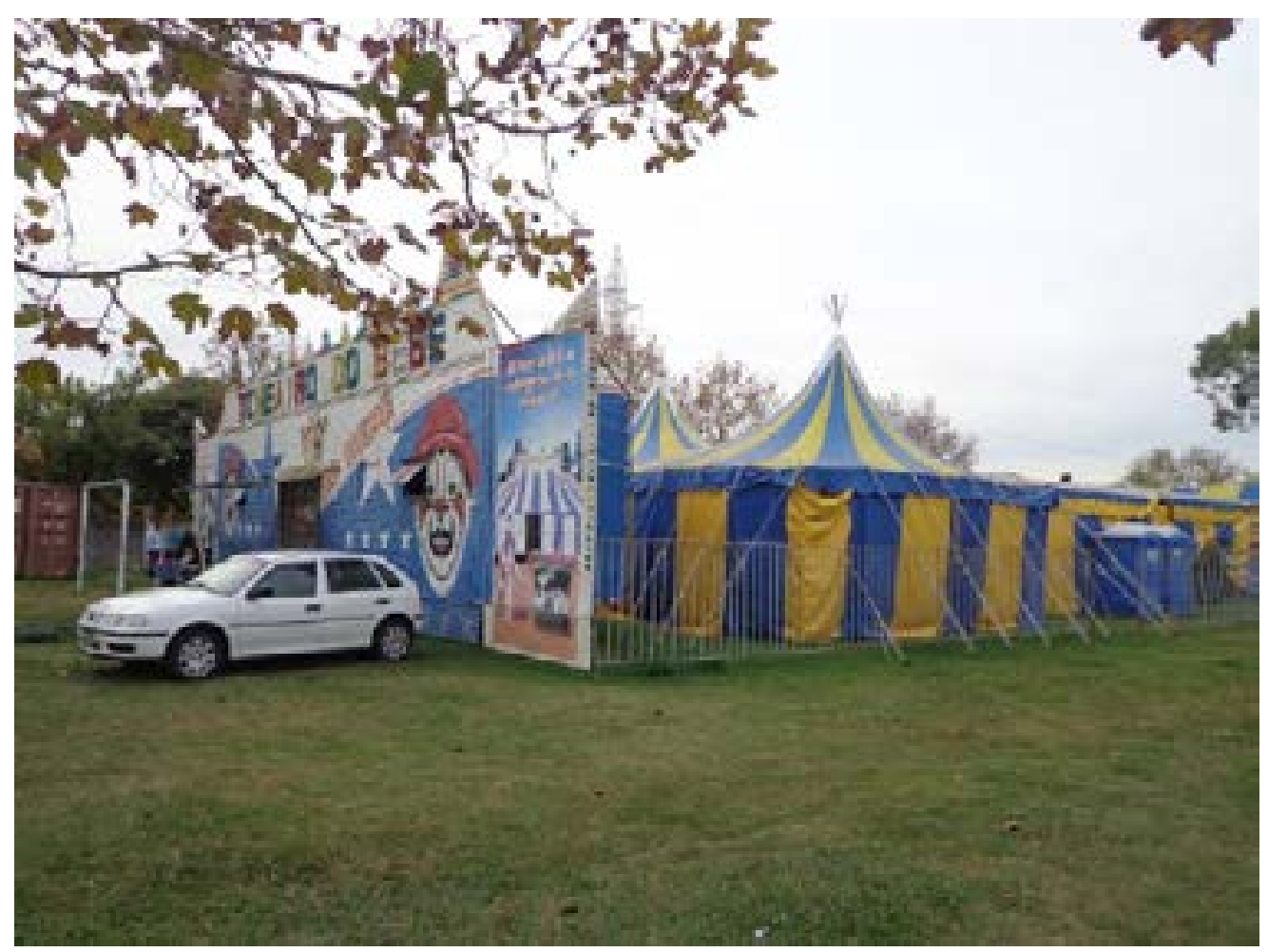

Figura 4 - Imagem que permite observar o espaço do teatro em 3 planos. Primeiramente, o trailer que dá lugar à bilheteria e saguão de entrada. No segundo plano, duas lonas menores com mastros centrais, onde são comercializados os alimentos e bebidas. Ao fundo, a lona maior que dá acesso ao público e ao palco. Foto do autor. Em 11 mai. 2013. Rio Grande-RS.

A atividade dos circos-teatro desafia uma prerrogativa pessimista do fim iminente dessa atividade teatral.Apesar de tudo, elapersiste na atualidade alternando-se em períodos de vigor e de crise, e, assim como outras expressões culturais,ela não escapou ilesa às complexas tramas em torno da culturaque permeiam a sociedade contemporânea. Enquanto uma expressão artística cômica em um mundo marcado por rupturas, o circo-teatro, do qual Bebé é continuidade, atravessou tempos de mudanças e se constituiu nessas intermitências. Internamente, nas relações do grupo/ família, existem relatos que destacam essas dificuldades de adaptação e de diálogo com as transformações culturais dos tempos atuais, mas, além do destaque dado aos conflitos e dificuldades, também aparecem relatos de momentos felizes e memórias marcantes. Estes momentos, assim como os esquecimentos, as rupturas, as disjunções e os traumas que compõem "a persistência de mundos sociais e culturais dentro dos atormentados universos contemporâneos" (Berliner, 2011, p.11), são parte das manifestações culturais e são também elementos que pairam entre a permanência e a transformação.

No Teatro do Bebé, família e profissão andam juntas e é nesse aspecto que se coloca um diferencial do artista de circo-teatro. A transmissão dessas memórias familiares/profissionais vai além do espetáculo finalizado, esse processo se manifesta na estética do trabalho, nas estruturas organizacionais e gerenciais da companhia, no desempenho da função que cada indivíduo exerce dentro e fora da cena, ou seja, em tudo aquilo que está atravessado pelo conhecimento daqueles que já não estão mais presentes. Como bem lembra Candau (2012, p. 118), "transmitir uma memória é fazer 
viver" sendo não somente algo que é repassado, mas também "uma maneira de estar no mundo". Sendo assim, o intangível passa à materialidade, pois:

[...] a aquisição de uma identidade profissional ou, mais genericamente, de uma identidade vinculada a poderes e saberes não se reduz apenas a memorizar e dominar certas habilidades técnicas: ela se inscreve, na maior parte dos casos, nos corpos mesmos dos indivíduos (Candau, 2012, p. 119).

Dessa forma, o cômico personifica a própria memória do circo-teatro.Todavia, naatividade contemporânea do circo-teatro, a memória opera de forma a não manter um arquétipo fixo de trabalho, pois sua maleabilidade frente aos novos momentos culturais é também a garantia da manutenção do trabalho artístico, e de persistência dessa memória viva. Existe, no trabalho, a liberdade de diálogo e a incorporação do cotidiano e de aspectos contemporâneos da cultura de massa. Considerando que a noção de patrimônio parte de uma compreensão de que a atividade que o grupo/família desenvolve pode ser registrada, que pode ter um significado para um conjunto, para uma comunidade, ou enquanto uma memória que carrega, é possível perceber que, no caso do Teatro do Bebé, essa compreensão é complexa.

O grupo não se vê historicamente e memorialmente da mesma forma como o pesquisador de fora pode percebê-lo, e a preocupação impreterível de todos os artistas da família é com a possibilidade de serem ouvidos em suas reivindicações básicas para continuarem obtendo seu sustento através do teatro itinerante. A compreensão de patrimônio, nesse caso, não está aprofundada como, por exemplo, em manifestações como o Tambor de Crioula, ou o Samba de Roda, ou o Ofício das Baianas do Acarajé $^{17}$ entre outros, nos quais já há toda uma discussão junto às comunidades, e também onde os experts e os poderes públicos outorgaram o reconhecimento oficial.

Conforme Pimenta (2005), o aspecto do nomadismo, ao mesmo tempo em que identifica a prática popular do circo-teatro, é também o que dificulta a transmissão do conhecimento e o que não dá garantias à própria sobrevivência dessa forma de teatro a qual marcou época dentro dos grandes circos. A autora aprofunda tal afirmação com as seguintes palavras:

[...] o circo-teatro não faz parte da cultura desta ou daquela região, não é arte de um lugar específico, portanto, não faz parte de um folclore regional, o que, provavelmente, garantiria sua preservação. Não há responsáveis por sua manutenção, a não ser dentro da própria comunidade circense, que participa do processo evolutivo do circo atendendo às suas necessidades práticas e que, portanto, não tem o devido distanciamento para compreender a importância da preservação do circo-teatro como fenômeno histórico (Pimenta, 2005 p. 26-27).

Outro ponto importante, para se pensar sobre o saber-fazer do circo-teatro no campo do patrimônio, está no seu diálogo direto com os meios de comunicação de

17 Bens culturais registrados pelo Instituto do Patrimônio Histórico e Artístico Nacional (IPHAN) como patrimônios imateriais brasileiros. Dossiês disponiveis em: http://portal.iphan.gov.br/pagina/detalhes/606/. Acesso em 07 de março de 2016. 
massa. Durante o trabalho de campo, na convivência com o grupo nos bastidores e nas entrevistas realizadas, em inúmeras vezes Bebé trouxe comparações de situações com telenovelas ou assuntos midiáticos relativos a personagens consagrados pela indústria televisiva da atualidade. Alguns chistes e situações de riso em cena também traziam músicas de grande apelo popular do momento, ou assuntos relativos a programas da televisão aberta e de grande alcance de público. Inúmeras vezes contrastavam, na cena, um cenário pictórico e elementosreais (mobiliário moderno), ou um figurino que remetia ao passado, usado por um ator que contracenava com outro que se vestia com as "roupas da moda". Programas de rádio, televisão, filmes do cinema, nomes de redes sociais da internet escapavam nas brincadeiras do palhaço em cena, ora dialogando, ora se opondo ao próprio texto do espetáculo, que continha palavras rebuscadas de outras épocas perceptíveis geralmente nas deixas dos "escada" 18 que seguiam o roteiro de cena. Esse confronto de tempos também se tornava engraçado, uma vez que esse entremeio, que separa o passado da cena antiga do espetáculo de circo-teatro e as referências atuais, acabava por tornar-se substância para o riso, conforme a situação.

O entrelaçamento de elementos da cultura televisiva com a cultura popular está presente também em outras manifestações. Segundo Adriana Schneider Alcure, em relação ao mamulengo da Zona da Mata pernambucana, quando em atividade de campo com o mestre mamulengueiro que fez parte da sua pesquisa, observou que este buscava inspiração em programas de televisão do gênero popular para a criação das histórias que posteriormente eram encenadas com os bonecos. A pesquisadora avalia essa questão da seguinte maneira:

[...] uma coisa muito interessante de se observar é esse lugar idealizado desse encontro com a cultura popular. Às vezes o pesquisador vai querendo buscar a matriz, a origem, e às vezes o ouro está no Domingão do Faustão. O ouro no seguinte sentido, o ouro no lugar de você compreender, e de você dialogar com o nosso próprio tempo. E perceber o nosso tempo é sempre muito difícil. Nós estamos sempre perpassados por preconceitos e por uma série de questões. Mas não tem como a gente compreender o mamulengo sem a gente entender o tempo em que a gente vive $[\ldots] 19$.

Paralelamente ao uso de aspectos dos meios de massa em seus espetáculos, a televisão também é apontada pelo cômico Bebé como fator causador de situações que trouxeram alterações ao circo-teatro:

[...] as temporadas antes eram maiores, as peças também eram, se podia levar uma porção de peças, hoje não, por causa da televisão... Então tem o dia certo da novela, o dia em que vão revelar quem é o pai do Jorginho [personagem da telenovela "Avenida Brasil" da Rede Globo, que estava sendo transmitida à época da entrevista]. Atrapalha, né. [...] Na época essas peças "Direito de nascer", "La cumparsita", "Dama das Camélias", tudo isso ia sempre na segunda-feira quando

180 ator "escada" ou "crom", na linguagem circense, é o ator secundário que trabalha de dupla com o cômico principal (Bolognesi, 2003, p. 58). No caso da família pesquisada, é utilizado entre o grupo o termo "escada", para todos que interpretam personagens que, dentro do enredo, preparam a situação para que o palhaço possa fazer as intervenções cômicas e os chistes.

19 Adriana Schneider Alcure, em aula proferida no Curso Livre de Folclore e Cultura Popular 2012. CNFCP/IPHAN. Rio de Janeiro. 
era o cartaz máximo da semana que era para fazer público. Mas hoje não, hoje eu tenho que fazer na segunda-feira à noite uma promoção, duas pessoas vão pagar uma mixaria que é para trazer o público, antigamente não. Então tudo isso modifica. Ah! E hoje tenho que ver se o Grêmio joga com quem, se vai passar na televisão, aí não dá para trabalhar e tudo isso incomoda (informação verbal)20.

Como se percebe, Bebé analisa muito bem as situações, adapta-se a elas e se utiliza delas como insumo para a cena e para o trabalho em geral. O circo-teatro, para subsistir na atualidade, precisa trabalhar com tais ambiguidades e isso o palhaço Bebé demonstra fazer com bastante habilidade. Nas justificativas vindas do público, que frequenta o teatro para a empatia com Bebé, ouve-se: "porque ele mexe com as pessoas", "porque ele brinca com o povo" ou "mesmo sendo a mesma uma peça não é igual à outra", sentenças que denotam a sua habilidade de improvisar. Dentro e fora da lona o palhaço precisa ter flexibilidade para atuar em situações bastante adversas. Nesses dois papéis, no de cena e no da vida, há a exigência da flexibilidade do homem/palhaço, pois esses dois níveis de improvisação se complementam.

Visto que as novas tecnologias se apresentam como um possível problema, elas são também fonte de inspiração para o trabalho cênico. Há o rearranjo, a utilização daquilo que é do hoje para garantir a continuidade de uma prática composta por traços do passado, ações essas desempenhadas de forma muito competente pelo cômico Bebé. Esse redimensionamento dos textos tradicionais da companhia e da atividade do cômico às temáticas de seu tempo tornou-se marcante, principalmente frente à necessidade de manter a atividade teatral da família.

A oposição tradição/modernidade se dilui no que se refere ao circo-teatro, uma vez que ele não representa um compromisso com uma ideia de originalidade em relação ao passado, pelo contrário, está sempre se atualizando com o seu tempo e agregando elementos contemporâneos. No entanto, características primordiais como o nomadismo, a transmissão oral dos conhecimentos e os aspectos que remetem à comicidade popular e ao realismo grotesco continuam vigentes, por vezes reconfiguradas, mas sempre presentes. Com relação a esse embate, referente às noções de diálogo entre modernidade e tradição, Ramirez (2010, p.17) afirma a necessidade de buscarmos "novos conceitos e marcos interpretativos" em relação ao tema da tradição de forma que esse paradoxo fosse substituído e desse lugar a um modelo "triádico ou sistêmico".

A discussão urdida a partir do Teatro do Bebé permite provocações que levam a discutir a própria ideia de tradição e vê-la em uma perspectiva temporal diferenciada. Sendo a tradição uma construção do presente em relação ao passado, uma espécie de "filiação invertida", pois são os filhos no presente que buscam dar sentido, reconhecimento à sua paternidade (Lenclud, 1987), no Teatro do Bebé, paralelamente ao passado, estão presentes os referenciais contemporâneos que ressignificam, recriam, retradicionalizam essas memórias frente a inconstância e a velocidade dos tempos atuais. Assim, o passado integra-se ao devir e juntos dão sentido à tradição do circo-teatro. 
A prática artística dos circos-teatro levou teatro e entretenimento para as periferias e para o interior do país quando não se pensava nas novas tecnologias. Depois, como expressou Sousa Júnior (2008), alimentou os novos meios de cultura massiva, como os programas de televisão. $O$ Teatro do Bebé reúne características dessas duas épocas, ele resiste reaglutinando memórias e necessidades, passados e presentes, enquanto estratégias para seguir existindo. Dessa maneira, em que lugar se coloca o Teatro do Bebé frente às políticas de patrimônio, uma vez que em seu saber-fazer está presente uma atividade geradora da cultura de massa da qual também se retroalimenta? Para Alves,

[...] de um modo geral, as declarações, convenções e recomendações sobre a diversidade cultural, o patrimônio cultural imaterial e as culturas tradicionais e populares abrigam, cada um a sua maneira, certo desconforto e uma dificuldade de compatibilizar os conteúdos e expressões das chamadas culturas tradicionais e populares com as novas tecnologias digitais de comunicação e informação. (Alves, 2010, p. 551)

Quando a ciência ainda não se voltava claramente para a discussão de conceitos como a interculturalidade e os processos de globalização ou hibridação cultural, os artistas itinerantes e seus teatros, através de suas andanças por diferentes lugares do país, traziam consigo essa multiplicidade de influências culturais que iam sendo adquiridas nos contatos e nas trocas realizadas ao longo do caminho. Como hoje se realiza pelos meios tecnológicos e de informação as trocas culturais que caracterizam as infinitas expressões humanas, as companhias de teatro itinerantes formavam uma espécie de rede que interligava pequenos mundos isolados. Levavam em seus trabalhos as influências dos lugares por onde passavam, e a transmitiam a outras realidades. Estavam ligados ao seu tempo com influências entre grandes e pequenas comunidades, eram uma via de expressão dessas diferenças, já que estavam colocados numa linha que não os prendia nas relações rígidas de um meio fixo ou isolado.

$\mathrm{Na}$ Câmara Setorial do Circo tem-se salientado a necessidade de preservação da memória dos circenses ${ }^{21}$. De outro lado, pode-se observar as reivindicações de Bebé por melhorias estruturais nas cidades por parte dos poderes públicos para a instalação dos circos (informação verbal) ${ }^{22}$. Nos dois casos, têm-se um objetivo em comum, mas com vieses diferentes. A Câmara Setorial quer valorizar o passado para que reflita no presente; Bebé espera políticas públicas no presente para garantir futuro da atividade. O comediante, mesmo que inconscientemente, deseja não se tornar somente memória do circo-teatro.

\footnotetext{
21 "Reconhecer, preservar e estimular a tradicional atividade das artes circenses; Compreender a pesquisa e a formação da memória como atividade permanente fundamental no processo de formação do artista; Entender os centros de formação como espaços naturais de preservação da memória, desenvolvimento da pesquisa, difusão do conhecimento e ainda como parceiros nos programas de inclusão digital; [...] Necessidade de regulamentação dos espaços de formação em circo, respeitando a natureza de como essa arte se apresenta/notório saber; [...] Ausência de programas de incentivo e registro da memória do circo no Brasil; [...] Urgência nos programas para registro e memória" (Brasil-Cnpc, 2010, p. 17).

22 Bebé. Entrevista. Op.Cit.
} 


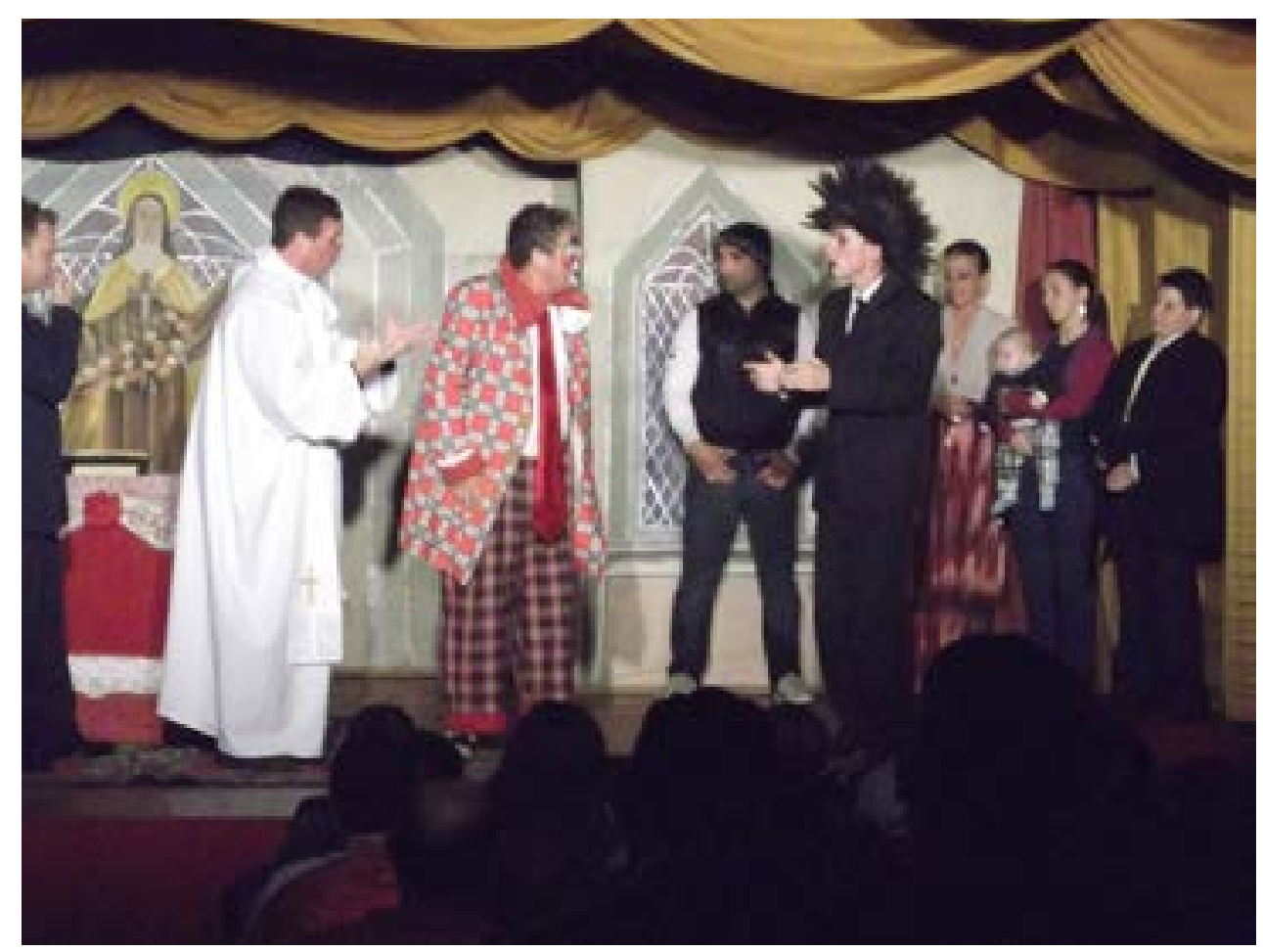

Figura 5 - Família Almeida em cena durante espetáculo. Palhaço Bebé ao centro da imagem. Foto do autor. Em 11 mai. 2013. Rio Grande-RS.

Sendo o patrimônio o alter ego da memória (Hartog, 2014, p. 193), há em seu conceito, e em tudo que ele vem a significar, uma grande plasticidade.A abrangência do patrimônio cultural nas últimas décadas tem trazido relações entre estado e comunidades, economia e sustentabilidade, desenvolvimento social e urbano, direitos autorais e cultura de massa e, através dos novos sujeitos que passaram a agir nesse âmbito, trouxe contradições e conflitos (Canclini, 1999, p.19). O circo-teatro pensado como uma manifestação que envolve um saber-fazer do passado, tradicionalizado no espaço da lona-casa e na interação atores-público, presente na memória familiar e na memória coletiva dos espectadores, possibilita uma série de questionamentos em relação à patrimonialização. Afinal, o circo-teatro escapa de padrões de pensamento que visam à autenticidade, à pureza e à originalidade, aspectos relevantes nos discursos de proteção e reconhecimento do patrimônio cultural.

Assim, o circo-teatro, que pode ser visualizado como uma tradição de longa duração de algumas companhias itinerantes de Commedia dell'arte, ou como memória dos artistas dos shows de variedades dos primeiros tempos do teatro brasileiro, segue sendo também uma atividade contemporânea que vive da atualização dos espetáculos tradicionais e da tecnologia para incremento do trabalho.

Dessa maneira, a noção de patrimônio tem sido acionada para algum uso específico no presente, principalmente pelos Estados e poder público, e também por grupos organizados de detentores de manifestações culturais. Não sendo uma reivindicação do Teatro do Bebé, pode-se pensar que esse olhar sobre a companhia, ou outros grupos/família de circo-teatro,talvez só tivesse importância a essas pessoas se pudesseservir como um mecanismo para alçar a atenção básica necessária dos poderes públicos, não para regulamentar uma prática cultural dinâmica, ou mirando-a como "relíquia" ou algo a ser "musealizado". Mas um olhar de reconhecimento que 
possa possibilitar o entendimento do universo em que o grupo opera, garantindo sua permanência até quando eles, os protagonistas, assim desejarem.

\section{Considerações Finais}

O Teatro do Bebé não é algo ancestral enquanto atividade familiar, não se explica cosmologicamente como diversas manifestações culturais reconhecidas no Brasil por suas expressões ou enquanto celebração, pela dinâmica dos contatos coletivos de um lugar fixo, ou pelo savoir-faire entendido dentro da lógica de relação temporal de interação entre o homem e a natureza. Com o circo-teatro, vê-se ocorrer algo, no mínimo, curioso: a atividade não é uma expressão considerada popular dentro daquilo que até hoje foi reconhecido como patrimônio imaterial brasileiro, uma vez que envolve questões referentes à cultura de massa e a cultura comercial. A atividade teatral não possui uma carga de "autenticidade" que revela um aspecto da identidade de uma região, da qual a maioria da população reconhece aquela manifestação como uma "tradição regional".

O circo-teatro é adaptável aos costumes de determinada região, os atores itinerantes absorvem e transformam aspectos dos lugares por onde passam. Atuante nos contextos contemporâneos, essas companhias trazem as influências de seu tempo para dentro de seus espetáculos. A atividade teatral destas companhias tornou tradicional sua forma de organização a partir da junção de expressões e características culturais do cotidiano do modelo ocidental urbano desenvolvido a partir de meados do século XIX.

Se hoje o grotesco retomado na atividade pode remontar o passado da comicidade aos preceitos bakhtinianos, os teatros de lona a estilo do Teatro do Bebé poderiam ser considerados como aqueles grupos que resistem enquanto guardiões de uma teatralidade das ruas. Ou, então, quem sabe, como uma expressão das transformações do risível dentro de diferentes tempos e contextos culturais contemporâneos.

O espaço do circo, o teatro de outros tempos, a figura do palhaço, o nomadismo,o gênero da comédia, a infraestrutura do espaço cênico, a organização familiar e a maneira de gerir e se sustentar a partir do trabalho são pontos que passaram a dar sentido a um saber-fazer que se constituiu em uma forma peculiar de se colocar no mundo. A atividade artística não é uma atividade artesanal, como dos artesãos populares que, hoje, em diversas experiências das ações de reconhecimento patrimonial, transformaram essas técnicas em fontes de renda de modo a também garantir a continuidade do saber-fazer. Os espetáculos do circo-teatro sempre foram uma atividade mercadológica e de sobrevivência que foi incorporada à dinâmica da vida dessas pessoas, de famílias como a do palhaço Bebé.

O circo-teatro é resultado das vicissitudes da modernidade assim como também o é a noção de patrimônio cultural (Poulot,2009). Objetos de um mesmo tempo, a noção de patrimônio e a prática cultural do circo-teatro podem olhar-se mutuamente e indagar-se sobre seus sentidos. Entretanto, o patrimônio surgiu da emergência de preservar e salvaguardar a memória dos povos frente ao avanço da modernidade. Por sua vez, o circo-teatro, ou teatro de emergência, utilizando-se de elementos de 
diferentes tempos das artes, partiu da necessidade de levar a modernidade do teatro e da diversão aos rincões do país. Talvez, refletir sobre a noção de "emergência" possa auxiliar na compreensão dessas incongruências e na emersão de novos sentidos para o patrimônio cultural. 


\section{Referências}

ALBERTI, Verena. O riso e o risível na história do pensamento. $3^{a}$ ed. Rio de Ja neiro: Zahar, 2011.

ALCURE, Adriana Schneider. et al. A eficácia cômica do mamulengo da Zona da Mata pernambucana. 2012. Aula proferida no Curso Livre de Folclore e Cultura Popular 2012. CNFCP/IPHAN. Rio de Janeiro, 2012.

ALMEIDA, José Ricardo de. Palhaço Bebé. Entrevista concedida ao autor. Pelo tas/RS. 19 de agosto de 2012.

ALMEIDA, Silvério de. Entrevista concedida ao autor. Pelotas/RS. 28 de junho de 2012.

ALVES, Elder Patrick M. Diversidade Cultural, Patrimônio Cultural Material e Cultura Popular: a Unesco e a Construção de um Universalismo Global. In: Revista Sociedade e Estado - Volume 25, Número 3, Setembro/Dezembro 2010. p.539-560

ANDRADE JR. Lourival. Mascates desonhos: as experiências dos artistas de cir co-teatro em Santa Catarina - Circo-teatro Nh'Ana. Florianópolis: UFSC, 2000. 208f. Dissertação de Mestrado. Curso de Pós Graduação em História.

BAKHTIN, Mikhail. A cultura popular na Idade Média e no Renascimento:o con texto de François Rabelais. Tradução de Yara Frateschi Vieira. 7’a ed. São Paulo/ Brasília: Hucitec/Editora Universidade de Brasília, 2010.

BERLINER, David. Anthropologie et transmission. In: Terrain: Revue d'ethnologie de l'Europe. no 55. Septembre 2010, pp. 4-19. Disponível em: < http://terrain. revues.org/14035> Acesso em 20 de agosto de 2013.

BOLOGNESI, Mario F. Palhaços. São Paulo: Editora UNESP, 2003.

BRASIL. Conselho Nacional de Políticas Culturais (CNPC). Câmara e Colegiado Setorial do Circo. Relatórios de atividades 2005-2010. A Participação Social nas Políticas Públicas do Setor. Ministério da Cultura/ Conselho Nacional de Polí ticas Culturais/ Funarte, 2010. Disponível em: http://www.cultura.gov.br/cnpc/ wp-content/uploads/2011/07/plano-setorial-de-circo.pdf. Acesso em 14 de abril 2012.

BRASIL. Instituto do Patrimônio Histórico e Artístico Nacional. Bens Registrados. Disponível em: http://portal.iphan.gov.br/pagina/detalhes/606/. Acesso em 07 de março de 2016.

BURKE, Peter. Cultura popular na Idade Moderna. São Paulo: Cia. Das Letras, 1989. 
CANCLINI, Néstor Garcia. Los usos sociales del Patrimonio Cultural. In: CRIADO, Aguilar. Patrimonio Etnológico. Nuevas perspectivas de estúdio. Consejeria de Cultura. Junta de Andalucía, 1999.

CANDAU, Joël. Memória e Identidade. Trad. Maria Letícia Ferreira. São Paulo: Contexto, 2012.

CHARTIER, Roger. A história cultural: entre práticas e representações. Tradução Maria Manuela Galhardo. Rio de Janeiro: Bertrand Brasil, 1990.

CHARTIER, Roger. "Cultura Popular": revisitando um conceito historiográfico. In: Revista Estudos Históricos. Rio de Janeiro, vol. 8, n. 16, 1995, p.179-192.

FO, Dario. Manual mínimo do ator. Dario Fo; Franca Rame (org.). Trad. Lucas Bal dovino, Carlos David Szlack. 3a Ed. São Paulo: Editora Senac São Paulo, 2004.

GAZETA DE SANTA CRUZ DO SUL. Santa Cruz do Sul-RS. Data: 14/07/1950.

HALBWACHS, Maurice (1877-1945). A memória coletiva. São Paulo: Vértice, 1990.

HARTOG, François. Regimes de historicidade: presentismo e experiências do tempo. 1a ed. Belo Horizonte: Autêntica Editora, 2014.

HOBSBAWM, Eric J.; RANGER, Terence O. A invenção das tradições. Rio de Ja neiro: Paz e Terra, 2006.

LENCLUD, Gérard. La tradición no es lo que era.... In: Terrain: Revue d'ethnolo gie de l'Europe. O9 de outubro de 1987. Disponível em: $<$ http://clasesbosa. blogspot.com.es/2009/01/la-tradicin-no-es-lo-que-era-grard.html> Acesso em 07/11/2012.

PIMENTA, Daniele. Antenor Pimenta: circo e poesia: A vida do autor de - E o céu uniu dois corações. São Paulo: Imprensa Oficial do Estado de São Paulo: Cultura - Fundação Padre Anchieta, 2005.

PONTES, Fernando Augusto Ramos; MAGALHÃES, Celina Maria Colino. A Trans missão da Cultura da Brincadeira: Algumas Possibilidades de Investigação. In: Psicologia: Reflexão e Crítica, 2003, 16(1), pp. 117-124.

POULOT, Dominique. Uma história do patrimônio no Ocidente, séculos XVIII XXI: do monumento aos valores. Trad. Guilherme João de Freitas Teixeira. São Paulo: Estação Liberdade, 2009. 
RAMIREZ, Jesus Antônio Machuca. Patrimonio y retradicionalización en la cultura indígena y popular emMexico. In: FERREIRA, Letícia Mazzucchi; MICHELON, Francisca Ferreira (org.) Memória, patrimônio e tradição.PPG em Memória Social e Patrimônio Cultural, CAPES. - Pelotas: Editora e Gráfica Universitária - UFPel, 2010.

ROUBINE, Jean-Jacques. A linguagem da encenação teatral, 1880-1980. Tradu ção Yan Michalski. 2ª ed. Rio de Janeiro: Jorge Zahar, 1998.

SANTOS, Elaine. Entre lágrimas e risos: os serelepes e a memória do teatro itine rante. Tese de doutorado. Programa de Pós-graduação em Letras. Universidade Federal de Santa Maria, 2013.

SILVA, Ermínia. Circo-teatro: Benjamin de Oliveira e a teatralidade circense no Brasil. São Paulo: Altana, 2007.

SILVA, Ermínia; ABREU, Luís Alberto. Respeitável público... o circo em cena. Rio de Janeiro: Funarte, 2009.

SOUSA JUNIOR, Walter de. Mixórdia no picadeiro: circo, circo-teatro e circularidade cultural na São Paulo das décadas de 1930 a 1970. São Paulo: USP, 2008. $204 f$. Tese de Doutorado. Escola de Comunicações e Artes. Teoria e Pesquisa em Comunicação.

Recebido em: 21/06/2015 Aprovado em: 15/03/2016 